\title{
Economic Conditions Early in Life and Individual Mortality
}

\author{
By Gerard J. van den Berg, Maarten Lindeboom, and France Portrait*
}

Socioeconomic conditions during infancy and early-childhood years may affect mortality later in life. It is well documented that poor living conditions early in life are associated with susceptibility to a wide range of health problems later in life (see, e.g., Anne Case et al., 2005, and references therein). In bad times, the provision of sufficient nutrients and good living conditions for children and pregnant women may be hampered, and exposure to disease or malnutrition early in life may lead to an increase in mortality. Such effects have important policy implications. If being born in bad times has a positive long-run effect on mortality, then total lifetime earnings are reduced for those affected. ${ }^{1}$ This would increase the benefits of policies that help young children and pregnant women in recessions, for example, by way of enhanced provision of food, housing, and health care (see Douglas V. Almond, 2002, for a detailed discussion of policy implications).

The effects mentioned above have been difficult to analyze empirically. First, data often do not cover a sufficiently long time span to exam-

\footnotetext{
* Van den Berg: Department of Economics, Free University, De Boelelaan 1105, $1081 \mathrm{HV}$ Amsterdam, The Netherlands (e-mail: gberg@feweb.vu.nl); Lindeboom: Department of Economics, Free University, De Boelelaan 1105, 1081 HV Amsterdam, The Netherlands (e-mail: mlindeboom@econ.vu.nl); Portrait: IGW, FALW, Free University, De Boelelaan 1105, 1081 HV Amsterdam, The Netherlands (e-mail: france.portrait@falw.vu.nl). We thank the editor, two anonymous referees, Anne Case, Angus Deaton, Gabriele Doblhammer, Jutta Gampe, Paul Gregg, Sören Hojgard, Jim Oeppen, Chris Ruhm, and participants at seminars at Princeton University, the University of Michigan, University College London, Bristol, Cornell University, University of Copenhagen, and the Max Planck Institute for Demography (Rostock) and conferences on health and population economics and econometrics, in Lund, New York, and Stockholm, for helpful comments and suggestions. Márta Lopez provided excellent help with the empirical analyses. The "Historical Sample of the Netherlands Dataset release UZF.02" was kindly provided by the International Institute of Social History (IISG) in Amsterdam. A previous version of the paper was titled "Individual Mortality and Macro-Economic Conditions from Birth to Death."

${ }^{1}$ Kevin M. Murphy and Robert H. Topel (2003) demonstrate that the gains from mortality rate reductions have been enormous.
}

ine full lifetimes of individuals. Second, individual socioeconomic conditions during early childhood and health outcomes later in life may be jointly affected by unobserved heterogeneity, leading to simultaneity bias.

This paper analyzes the effects of economic conditions early in life on the individual mortality rate by using micro data with an observation window of unprecedented size, and by using macroeconomic conditions early in life as an "instrument" for the individual conditions. Macroeconomic conditions do not give rise to the aforementioned simultaneity bias because they are exogenous at the individual level. We separate cyclical fluctuations from secular trends in macroeconomic conditions; to capture the individual conditions early in life, we focus on the cyclical fluctuations of that period. We control for individual-specific background characteristics, contemporaneous conditions, and other individual mortality determinants. ${ }^{2}$

Our dataset, called the Historical Sample of the Netherlands (HSN), covers approximately 14,000 individuals born in the Netherlands in the period 1812-1912, followed up to the year 2000. It includes information taken from the standardized recordings of vital events (birth, marriage, and death) kept by municipalities and provinces. We merge these with historical timeseries data on macroeconomic variables, notably GNP, and with external information on the

\footnotetext{
${ }^{2}$ In demography, natural experiments have recently been applied to test effects of nutrition and disease exposure in utero and during the first months of life on mortality later in life, using longitudinal data. These studies are focused primarily on medical and not economic conditions. For example, Gabriele Doblhammer (2004) uses month of birth, and she surveys studies that use epidemics, wars, famines, or the rate of infant mortality in the cohort. The effect is often significant. Another related branch of literature focuses on the instantaneous effect of the business cycle on health and mortality (rather than the long-run effects we consider) in more recent years. M. Harvey Brenner (1979) and Christopher J. Ruhm (2000) consider instantaneous effects among adults. Rajeev Dehejia and Adriana Lleras-Muney (2004) consider instantaneous effects among children, as well as selection effects on the composition of newborns. We return to their results below.
} 
incidence of epidemics. There are no reliable nineteenth-century data on health expenditures and medical innovations, so one can not address their role in the causal chain from economic conditions to health to mortality. Also, the sample size precludes a detailed analysis of the effects of such specific policy measures as the abolition of child labor.

The empirical analysis consists basically of two stages. First, we make nonparametric comparisons between the lifetimes of individuals, notably of those born in a boom and those born in the recession that directly follows the boom. Second, we estimate duration models for individual mortality where, for a given individual at a given moment in time, the mortality rate depends on current conditions, conditions earlier in life, and other characteristics. The main outcomes are in strong agreement. The state of the business cycle at birth affects mortality later in life. This supports the view that economic status early in life is a key determinant of health and mortality in adulthood.

The paper is organized as follows. Section I presents the data and discusses variables that we use in the analyses. Section II provides nonparametric analyses. Section III covers the estimation of the duration model, including sensitivity analyses, and outlines policy implications of the results. Section IV concludes.

\section{The Data}

\section{A. Individual Records}

The HSN data are derived from the registers of birth, marriage, and death certificates (see Kees Mandemakers, 2000, for a general description in English). Currently, we have access to a cleansed sample of 13,718 individuals. This is a random sample of individuals born in the provinces of Utrecht, Friesland, and Zeeland between 1812 and $1922 .{ }^{3}$ The end of the observation window is December 31, 1999. The data provide the timing of vital life events, as well as household and family characteristics recorded in the registers noted above, like the occupation

\footnotetext{
${ }^{3}$ At the time, the Netherlands had 11 provinces. Our three provinces were jointly rather representative of the Netherlands in terms of economic activity. Aggregate mortality rates in our data display similar patterns as historical national averages.
}

TABle 1 -Descriptive Statistics

\begin{tabular}{lcc}
\hline \hline Variable & Average & $\begin{array}{c}\text { Standard } \\
\text { deviation }\end{array}$ \\
\hline Female (\%) & 49.8 & \\
Social class (range 1-6): & 2.29 & 1.3 \\
Father not illiterate (\%) & 84 & \\
Mother unmarried at birth (\%) & 2.0 & \\
Share agriculture in GNP (\%) & 24.46 & 3.3 \\
Log real per capita GNP at birth & 7.41 & 0.26 \\
$\begin{array}{l}\text { Lifetime duration men: } \\
\quad \text { median = 35.2 }\end{array}$ & 38.1 & 35.2 \\
$\quad$ Lifetime duration women: & 40.8 & 35.9 \\
$\quad$ median = 41.2 & & \\
\hline
\end{tabular}

Notes: Annual real per capita GNP is measured in 1,000 euros with 1995 as the base year. Reported moments and medians are based on uncensored lifetimes only.

of the father, whether the father was illiterate, gender, and geographic location.

The individual lifetime durations are observed in days. If the individual is still alive at the end of 1999, we do not observe the date of death. We therefore restrict attention to individuals born before 1903. We observe dates of death of migrants out of the provinces. For some individuals in the sample born before 1903, the date of death is missing or has not been collected yet. The rate at which this occurs decreases quickly over time, from 21 percent for those born in 1812-1821 to around 6 percent for those born in later cohorts. Occasionally, marriage and/or childbirth dates of such individuals are observed, and in that case we rightcensor the lifetime duration at the latest of these dates. Otherwise, the lifetime duration is rightcensored at zero, and the individual is discarded from the data. Missing values of explanatory variables lead to an additional loss of individuals from the sample. The sample used below contains 9,276 individuals.

We map the occupation of the father into a social class code ranging from 1 (lower lower) to 6 (upper upper). ${ }^{4}$ The place of residence at birth is translated into a binary urbanization indicator (being 1 if and only if the individual is born in a city). Table 1 gives summary statistics

\footnotetext{
${ }^{4}$ Codes 1 to 6 represent occupations like: diker, day laborer, dock worker (1), cow milker, beer brewer, florist (2), potato farmer, barber (3), bailiff, corn dealer, miller (4), factory manager, headmaster, infantry captain (5), and auditor, lawyer, pharmacist, surgeon (6), respectively.
} 
for the explanatory and endogenous variables. ${ }^{5}$ The lifetime statistics are for individuals whose date of death is observed.

We should note that the mortality rate as a function of age displays the familiar U-shaped curve. Among the uncensored observations, 25 percent died within a year. For ages up to five, the mortality rate is highest among the cohorts born in the middle of the nineteenth century.

\section{B. A Brief Overview of Historical Developments Related to Mortality}

Before we discuss the data on macroeconomic conditions and historical events, we give a brief outline of the historical and economic developments related to mortality in the Netherlands in the era we consider. (Note, however, that the empirical analysis is not primarily concerned with secular developments, but rather with cyclical fluctuations.)

The nineteenth and twentieth centuries witnessed a transition from a rather poor agricultural society with high mortality rates to a rich society with a large service sector and low mortality rates. In the first half of the nineteenth century, the growth rate lagged behind those of neighboring countries. Large-scale industrialization did not take off before the third quarter of the nineteenth century, which is relatively late (Joel Mokyr, 1974; Jan de Vries, 2000).

By 1830, large epidemics had been absent for almost a century, but the period 1830-1875 contained a number of dramatic epidemics, exacerbated by the rise in urbanization. ${ }^{6}$ The cholera epidemics of 1848-1849 and 1866-1867 and the smallpox epidemic of 1870-1872 each led to over 20,000 deaths nationwide (about 0.7 percent of the population). At the height of such epidemics, the national annual mortality rate was around 25 percent higher than normal. There were frequent smaller cholera epidemics. In towns and cities, in particular, living standards were often poor, sanitary conditions were bad (Abram De Swaan, 1988), and infectious and parasitic diseases were the primary causes

\footnotetext{
${ }^{5}$ See, e.g., Jan-Pieter Smits et al. (2000) for aggregate time series on birth and mortality in the nineteenth century. The national population grew from 2.2 million in 1812 to 3.4 million in 1862 , and to 6.1 million in 1912 .

${ }^{6}$ The single notable later epidemic is the influenza epidemic of 1918 .
}

of death (see Robert I. Woods et al., 1988, and Judith Wolleswinkel-van den Bosch et al., 1998, on the strong negative health effects from early industrialization and urbanization in Britain and the Netherlands). After 1875, mortality rates dropped spectacularly. This was the result of better availability of food, the dissemination of nutritional, hygienic, and medical knowledge among the population, and large improvements in public health provisions like sewage and water supply (Wolleswinkel-van den Bosch et al., 1998).

In the first half of the twentieth century, mortality was further reduced. The improvements in socioeconomic environment ${ }^{7}$ and more widespread tuberculosis control are thought to have been the most important determinants (see Wolleswinkel-van den Bosch et al., 1998). In the last decades of the twentieth century, mortality rates were reduced further, to the particular advantage of older age groups. This is due to improvements in medical technology and medical care (David M. Cutler and Ellen Meara, 2004).

\section{Data on Macroeconomic Conditions, Business Cycles, and Historical Events}

We merge the individual data records with external information. Most importantly, we use historical time-series data on annual GNP throughout the observation window. ${ }^{8}$ Our choice of GNP, instead of obvious alternatives such as GDP, is driven by the need for mutually consistent observations for as many years as possible. Figure 1 plots the log annual real per capita GNP for the interval during which the sample members were born. Clearly, in addition to the upward trend, there are many cyclical fluctuations. Jan Jacobs and Smits (2001) provide a detailed analysis of GDP movements in the Netherlands in the nineteenth century. Years with low and negative growth are observed more frequently than in the twentieth century. The GDP fluctuations are strongly correlated to the business cycles in the United Kingdom and

\footnotetext{
${ }^{7}$ There was a period of rapid growth after World War I, which ended with the Great Depression of the 1930s (Jan Luiten van Zanden, 2000).

${ }^{8}$ Details on data replication are available on the AER Web site (http://www.e-aer.org/data/mar06_data_20040207.zip).
} 


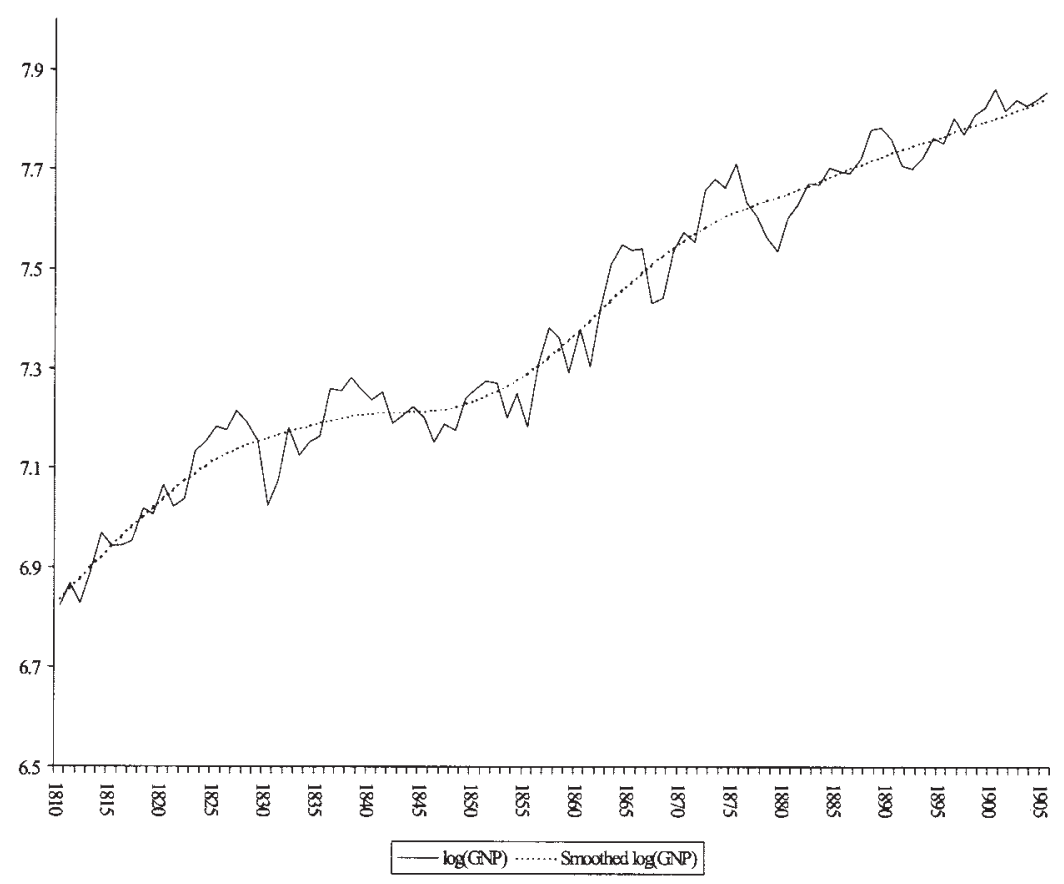

Figure 1. Log Annual Real Per Capita GNP

United States. We also consider other macroeconomic indicators, like the inflation rate and the share of agricultural production in annual GNP (see also Smits et al., 2000).

To capture the long-run effects of conditions early in life, we compare individuals born and raised in good times to those born and raised in bad times, following the line of thought that high GNP goes along with better individual economic conditions for many individuals. For our purposes, however, good and bad times are not well represented simply by the level of GNP. An era with high GNP also leads to innovation and investment in hygiene and health care, which decreases mortality later in life for those born in this era. These can be labeled secular effects. The effects of cyclical movements in GNP, contrary to the effect of the trend value or current level of GNP, are not dominated by these secular developments. At the individual level, cyclical changes often involve unexpected income shocks. Indeed, the turbulence created by the cycle may itself lead to health problems (we return to this in Section IIID).

Ideally, one would like to compare cohorts born in booms to those born in recessions ${ }^{9}$ with otherwise identical circumstances throughout life. This is infeasible due to secular improvements over time. In practice, one may compare a cohort born in a boom to a cohort born in the subsequent recession, because the latter benefits more from secular developments than the former, so that a decrease in expected lifetime can be attributed to the cyclical effect. More generally, one may relate the mortality rate to the state of the business cycle early in life. To proceed, therefore, one needs to assign a value of a cyclical indicator to each year. Most results below are based on a trend/cycle decomposition of $\log$ annual real per capita GNP, using the Hodrick-Prescott filter with smoothing parameter 500. The values of the cyclical terms are very robust with respect to the actual decomposition method and smoothing parameter, as are the resulting intervals within which the terms are positive or negative. We are therefore in the

\footnotetext{
${ }^{9}$ With some abuse of language, we use the terms boom and recession to denote years in which current log GNP is above or below its trend level. See Section IIIA for the formal definition used.
} 
fortunate position that booms and recessions are clearly identifiable in the data. Moreover, the empirical analysis provides virtually identical results if other decomposition methods are used. Figure 1 displays the cycle and trend as functions of calendar time. Below, we occasionally round off the value of the cyclical term to a binary outcome.

We also use external information on the incidence of epidemics and war, because these cause pronounced spikes in the mortality rates. World War II was the only war and occupation on Dutch soil since the era of Napoleon I. It included a famine of unprecedented severity in the winter of $1944 / 1945$, when mortality rates peaked because of malnutrition. (Jewish genocide victims were excluded from the data.) There are no reliable macroeconomic statistics for the World War II period, so we represent it by a separate dummy variable.

The price to be paid for the fact that the observation window is of unprecedented size concerns the absence of a number of variables often used in the mortality literature but unobserved in nineteenth-century records. Notably, we do not observe the individual's cause of death, aggregate amounts of health expenditures, or number of medical innovations.

\section{Descriptive and Nonparametric Analyses}

We start with a nonparametric comparison of the average lifetimes in a cohort born in a single boom to those in the cohort born in the subsequent recession. To prevent that the latter is smaller simply due to instantaneous effects of economic conditions on infant mortality, we condition on survival until age two or age five. We require that the boom and recession not include an epidemic, and we require that both last at least three years, in order to have reasonable sample sizes. We also ignore the period after 1881 because the strong upward trends in GNP and lifetimes in that era may dominate the comparison. Consider the boom of 1872-1876 and the subsequent recession of 1877-1881. Among those born in the boom, the average of $T \mid T>2$ equals 66.0 years, whereas among those born in the recession, it equals 62.5 (both standard deviations are 1.5 years). So, despite the secular trend that works to the advantage of those born later (i.e., in the recession), the latter have shorter conditional lifetimes. Formally, we perform a one-sided test of the null hypothesis of equal means against the alternative that the mean in the recession is smaller. The test statistic value equals 1.7, which exceeds the 5percent critical value of the asymptotic standard normal distribution of the statistic under the null. For $T \mid T>5$, the results are similar. The averages equal 70.8 (1.2) and 67.5 (1.3), respectively, so the test statistic equals 1.9 , which is again significantly different from zero. For other boom-recession combinations we considered, the conditional average lifetimes are again smaller in the recession, but the tests do not result in rejection of the null hypothesis.

The tests above do not exploit all available data. To proceed, we perform a regression of $(\log )$ lifetimes on the binary boom (versus recession) indicator at birth, where we include dummy variables for being born in a particular "birth period" defined by a combination of a boom and the subsequent recession. Note that the latter dummy variables capture trends in average lifetimes across birth periods. We need to restrict attention to birth years before 1896 because the last birth years in the data (18961902) constitute a boom. As above, we consider only those individuals who survive beyond age two or age five. We ignore individuals born in years with epidemics. We expect that the strong upward trend in lifetimes after 1881 affects the parameter estimate for the boom indicator at birth, so we interact it with a dummy for the period after 1881 .

Table 2 contains regression results for the case where we condition on $T>2$. The results for $T>5$ and for regressions of $\log$ lifetimes are qualitatively similar. The coefficient of the boom indicator at birth is significantly positive, implying that individuals born in recessions have higher long-run mortality rates than those born in better times. Note that, as above, the test is conservative to the extent that it does not take account of secular improvements within birth periods that necessarily benefit those born later (i.e., in the recession). The interaction coefficient of the boom indicator and the dummy for Birth Period VIII (which is the period after 1881) is, as expected, significantly negative.

We also perform this regression on the subsample of the three birth periods in which the business cycle fluctuates the most (as defined by the maximum amplitude of the 
TABle 2-Parameter Estimates of Regressions of Conditional Lifetimes on the Binary Boom/Recession Indicator at Birth And the Birth Period Dummy Variables

\begin{tabular}{lcc}
\hline \hline Variable & Estimate & Standard error \\
\hline Baseline regression & & \\
Boom (instead of recession) at birth & 1.58 & $0.95^{*}$ \\
Birth Period I & 48.92 & 1.29 \\
Birth Period II & 46.42 & 1.18 \\
Birth Period III & 45.24 & 1.17 \\
Birth Period IV & 46.82 & 1.57 \\
Birth Period V & 48.72 & 1.80 \\
Birth Period VI & 57.05 & 1.33 \\
Birth Period VII & 63.19 & 1.18 \\
Birth Period VIII & 68.68 & 1.40 \\
Interaction boom at birth $\times$ Birth Period VIII & -5.16 & 2.01 \\
\# of individuals & 4774 & \\
\hline Three birth periods with strongest cycle only & & \\
Boom (instead of recession) at birth & 2.36 & $1.33^{*}$ \\
\# of individuals & 1885 & \\
\hline
\end{tabular}

Notes: * denotes significance at the 5-percent level according to a one-sided test of a zero effect of the boom/recession indicator at birth. In both regressions, the outcome variable is the individual lifetime conditional on survival beyond age two. The explanatory variables in the second regression include dummy variables for Birth Periods II, VI, and VII.

cyclical component or by the average of this component in the boom minus the average in the recession, leading in both cases to Birth Periods II, VI, and VII). The results are also in Table $2 .{ }^{10}$ Clearly, the coefficient of the boom indicator at birth is larger and more significant than above, which lends more weight to our conclusions. ${ }^{11}$

A disadvantage of the analyses so far is that they ignore periodicity of business cycles throughout the childhood years of an individual. Someone who is born in bad times is likely to experience good times during some childhood years, and vice versa, because good and bad times succeed each other with an average frequency of a few years. If conditions at birth, as well as during childhood, affect mortality later in life, the effect of the bad times at birth may

\footnotetext{
${ }^{10}$ We do not report the birth-period coefficients because they are virtually the same as for the baseline regression.

${ }^{11}$ Similarly, we detrended the time series of the average $\log$ conditional lifetime per birth year and regress it on the detrended $\log$ GNP. To reduce the noise due to measurement errors, we time-aggregate the detrended terms by using averages over five-year intervals. The estimated regression coefficient is positive, and the correlation coefficient equals 0.33 if we consider $\mathrm{E}(\log T \mid T>2)$ and 0.34 if we consider $\mathrm{E}(\log T \mid T>5)$. Time aggregation into smaller than five-year intervals leads to smaller but still positive correlation coefficients.
}

be mitigated by the effect of the good times during childhood. To proceed, in the next section we estimate duration models where the individual mortality rate is allowed to depend simultaneously on conditions at birth and on conditions during childhood. The estimation of these models exploits the variation in the timing of the stages of the business cycle across individuals, to disentangle the long-run effects of conditions at birth and during childhood. This leads to parameter estimates of the effect of cyclical conditions at birth on mortality later in life for given conditions during later childhood years. The duration analysis also controls for individual characteristics, and it incorporates infant mortality and secular trends within "birth periods," albeit at the expense of functionalform model assumptions.

\section{Duration Analysis}

\section{A. Models for the Individual Mortality Rate}

The individual mortality rate is the natural starting point of the specification of the model, because of our interest in mortality rate's dependence on economic conditions. As age is measured in days, we take it to be a continuous random variable. Let the variable $\tau$ denote current calendar time. We express the mortality 
rate $\theta$ of an individual at a given point of time in terms of the prevailing age $t$, individual socioeconomic and demographic background characteristics $X$, current macroeconomic conditions $z(\tau)$, the trend components and cyclical indicators $z_{t r}(\tau-t+i)$ and $z_{c}(\tau-t+i)$ of macroeconomic conditions earlier in life $(i \in$ $\{0, \ldots, t-1\})$, and various interaction terms. The $z$ variables are measured only once a year. In obvious notation,

$$
\begin{gathered}
\lim _{d t \downarrow 0} \frac{\operatorname{Pr}(t \leq T<t+d t \mid T \geq t, \tau, X=x)}{d t} \\
=\theta\left(t, x, z(\tau), z_{t r}(\tau-t+i), z_{c}(\tau-t+i),\right. \\
\text { with } i \in\{0, \ldots, t-1\}) .
\end{gathered}
$$

As our basic specification, we take $\log \theta$ to be linear in the age dependence function of $t$, in $x$, $z(\tau), z_{t r}(\tau-t)$, and, if $t \geq 1$, in $z_{c}(\tau-t)$ at birth, and the average of $z_{c}(\tau-t+i)$ over $i$ in the childhood age set $\{1, \ldots, \min \{6, t-1\}\}$. This specification requires some discussion. First, consider the cyclical indicators early in life. These are represented by the cyclical components of the decomposition of log GNP from Section IC, at the birth year, and averaged over the years corresponding to age one up to six. At $t=0$, these do not affect $\theta$. At $t=1$, only $z_{c}(\tau-1)$ affects $\theta$. At $t=3, \log \theta$ depends on $z_{c}(\tau-3)$ and on the average of $z_{c}$ in $\tau-2$ and $\tau-1$. To reduce disturbances due to measurement error in the values of the cyclical components, we summarize them into two dummy variables. ${ }^{12}$ Specifically, for the cycle in the birth year, we use a binary boom/recession indicator, and for the cyclical conditions in the childhood age set, we use a binary variable that captures whether the average cyclical component in this set is positive or not.

The secular long-run effects are captured by the trend component $z_{t r}(\tau-t)$ of the decomposition at the birth year mentioned above. The trend components in early childhood are typically very similar to this. Indeed, it is empirically difficult to disentangle the effects of the

\footnotetext{
${ }^{12}$ If a boom or recession defined this way consists of only one year, then it is subsumed in the surrounding recession or boom. Details are available at http://www. e-aer.org/data/mar06_data_20040207.zip.
}

trend component at birth and current log GNP, due to multicollinearity. Both variables are mostly increasing over time, and at the individual level the second variable can be captured relatively well by the sum of the first and an increasing function of age. We therefore mostly omit $z_{t r}(\tau-t)$ from the model specification. Similar problems arise if we add calendar time polynomials to the specification.

For the age dependence, we adopt a piecewise constant specification with ten different intervals $(0,1,2-6,7-14,15-34,35-59,60-$ $69,70-79,80-89,90+)$. Concerning $x$, we restrict attention to characteristics at birth as opposed to later in life, for the reason that the latter may be endogenous or confounded. For $z(\tau)$ we take log annual real per capita GNP at $\tau$, as well as dummy variables for years with epidemics and for World War II. The latter also captures the fact that the GNP variable is missing for that period.

We also estimate more general specifications allowing for various interaction effects between the mortality rate determinants. We are particularly interested in interactions between $t$ and $z_{c}(\tau-t)$, which arise if the mortality effect of economic conditions around birth varies over the course of a lifetime. By now there is substantial medical and epidemiological evidence that malnutrition of the mother during the final stages of pregnancy leads her child to have a particularly high incidence of health problems after the age of 50 (see, e.g., Ilona Koupilová, 1997). We also fully interact the age dependence and current log GNP. Babies may suffer disproportionally from bad current conditions. If ignored, this may be picked up by the estimated coefficient of the cyclical indicator at birth, which may then be biased.

As is well known, ignoring unobserved heterogeneity of mortality determinants across individuals may result in biased estimates of the duration model parameters (see van den Berg, 2001, for an overview). Unobserved heterogeneity poses an additional problem if the current individual hazard rate is allowed to depend on the value of an explanatory variable at a point of time in the past, but after the beginning of the spell; in our case, this is the cyclical indicator during early childhood years (see, e.g., James W. Vaupel and Anatoli I. Yashin, 1985). Basically, bad childhood years may give rise to selection of childhood survivors with favorable 
Table 3-Parameter Estimates of the Baseline Model for the Individual Mortality Rate

\begin{tabular}{|c|c|c|c|c|}
\hline Variable & Estimate & $t$-statistic & Estimate & $t$-statistic \\
\hline \multicolumn{5}{|l|}{ Individual background characteristics } \\
\hline Female & -0.10 & 4.3 & -0.10 & 4.4 \\
\hline Social class father at birth & -0.031 & 3.0 & -0.032 & 3.2 \\
\hline Father not illiterate & -0.07 & 2.2 & -0.07 & 2.0 \\
\hline Mother unmarried at the time of birth & 0.05 & 0.6 & 0.05 & 0.6 \\
\hline Born in urban area & 0.08 & 2.7 & 0.07 & 2.6 \\
\hline Born in province Utrecht* & 0.23 & 7.4 & 0.24 & 7.6 \\
\hline Born in province Zeeland* & 0.30 & 10.7 & 0.30 & 10.6 \\
\hline \multicolumn{5}{|l|}{ Business cycle early in life } \\
\hline Boom (instead of recession) at birth & -0.09 & 3.5 & -0.08 & 2.8 \\
\hline Cycle indicator for age 1 to 6 & 0.00 & 0.0 & 0.00 & 0.1 \\
\hline \multicolumn{5}{|l|}{ Contemporaneous macro conditions } \\
\hline 1849 cholera in Utrecht & 0.81 & 4.2 & 0.72 & 3.7 \\
\hline 1870-71 smallpox & 0.51 & 5.2 & 0.52 & 5.3 \\
\hline 1918 influenza & -0.25 & 1.4 & -0.16 & 0.9 \\
\hline World War II (GNP missing) & -2.88 & 10.5 & -2.01 & 6.3 \\
\hline Current $\log ($ annual real per capita GNP) & -0.36 & 11.2 & & \\
\hline idem at age 0 & & & -0.33 & 3.7 \\
\hline idem at age 1 & & & -0.46 & 2.5 \\
\hline idem at age $2-6$ & & & -0.91 & 5.1 \\
\hline idem at age $7-14$ & & & -1.35 & 5.0 \\
\hline idem at age $15-34$ & & & -1.42 & 9.3 \\
\hline idem at age $35-59$ & & & -0.26 & 6.0 \\
\hline idem at age $60-69$ & & & -0.27 & 6.5 \\
\hline idem at age $70-79$ & & & -0.24 & 6.5 \\
\hline idem at age $80-89$ & & & -0.27 & 7.0 \\
\hline idem at age $90+$ & & & -0.27 & 4.3 \\
\hline \multicolumn{5}{|l|}{ Age } \\
\hline Age 0 & 1.30 & 5.5 & 1.07 & 1.6 \\
\hline Age 1 & 0.04 & 0.2 & 0.79 & 0.6 \\
\hline Age 2-6 & -1.24 & 5.2 & 2.81 & 2.2 \\
\hline Age $7-14$ & -2.45 & 10.1 & 4.93 & 2.5 \\
\hline Age $15-34$ & -2.27 & 9.4 & 5.74 & 5.0 \\
\hline Age $35-59$ & -1.86 & 7.3 & -2.66 & 8.0 \\
\hline Age $60-69$ & -0.63 & 2.4 & -1.42 & 4.3 \\
\hline Age $70-79$ & 0.47 & 1.8 & -0.50 & 1.6 \\
\hline Age $80-89$ & 1.44 & 5.2 & 0.59 & 1.8 \\
\hline Age $90+$ & 2.25 & 7.8 & 1.42 & 2.5 \\
\hline - log likelihood & \multicolumn{2}{|c|}{29067} & \multicolumn{2}{|c|}{29017} \\
\hline \# of individuals & \multicolumn{2}{|c|}{9276} & \multicolumn{2}{|c|}{9276} \\
\hline
\end{tabular}

Notes: Effects on log mortality rate reported. GNP-related variables are not mean-centered.

* Province Friesland as reference.

characteristics. Thus, if unobserved heterogeneity is present but is not taken into account, the effect of the cycle during early childhood may be biased. The dynamic selection effect can, however, be expected to generate a positive relation between the cycle during early childhood and observed mortality later in life. If we find a negative effect without taking account of unobserved heterogeneity, then the true effect is likely to be at least as negative. In the empirical analysis, we also estimate models in which an unobserved heterogeneity term is added to the expression for the log individual mortality rate. We assume that this term has a flexible discrete mass-point distribution in the population of newborns. In Section IIIC, we briefly address whether the composition of the population of newborns depends on macroeconomic conditions.

\section{B. Estimation Results}

Table 3 presents the estimation results for the basic model specification, with and without in- 
teractions between $t$ and $z(\tau)$. The estimates concern the mortality rate, so a positive value is associated with a shorter lifetime. The time unit is one year.

The most striking result is that the cyclical indicator in the birth year has a significantly negative effect on the mortality rate later in life. We take this as evidence that, at the individual level, economic conditions at birth have longlasting effects on mortality. Selection due to unobserved heterogeneity cannot explain this result, because it would give a positive coefficient. Allowing for interaction effects between age and current macroeconomic conditions gives a slightly smaller absolute value of the coefficient of the cyclical indicator in the birth year, but it remains significantly negative. It implies that the state of the cycle in the birth year gives rise to a difference of up to 8 percent in the mortality rate after the first year of life. As we shall see in Section IIID, this is roughly comparable to the effect of 10 to 15 years of additional secular developments, so in that sense it is comparable to being born 10 to 15 years later. The cyclical indicator at ages one to six does not have a significant effect on mortality later in life. One may argue this is because of a negative causal effect and a positive selection effect. The result does not change, however, when allowing for unobserved heterogeneity (see below).

Current log annual real per capita GNP has a significantly negative estimated instantaneous effect. Recall that this effect incorporates all secular effects from birth to current age. The coefficient should therefore not be interpreted as an (average) individual income elasticity. ${ }^{13}$ The size of the effect varies with age. A likelihood ratio test of the restriction that the effect is age-independent results in rejection. The estimated effect is largest for individuals between the ages of 15 and 34. Again, this may reflect an instantaneous effect, but may also reflect secular developments accumulated up to the current age.

The model specification allows for the cholera epidemic in Utrecht in 1849, the smallpox epidemics in Utrecht in 1870 and in Friesland and Zeeland in 1871, and the influenza epi-

\footnotetext{
${ }^{13}$ See also Lant Pritchett and Lawrence H. Summers (1996) for a discussion on this.
}

demic of 1918, as these are typically regarded to be the most severe. The effects of other epidemics are insignificant and are omitted (see below for more details).

Women, individuals from a higher social class, and individuals from rural areas have lower mortality rates than their counterparts. The finding with respect to social class is consistent with the large literature on the healthincome gradient. ${ }^{14}$ Individuals who are born in Friesland have a much lower mortality rate. This is a well-known result (see, e.g., Frans van Poppel and Mandemakers, 2003) and is explained by the high prevalence of breastfeeding in Friesland and the bad quality of water in the other two provinces. The mortality rate is a standard U-shaped function of age. Note that this cannot simply be read off from the coefficients of the piecewise age dependence function, because the effects of the cyclical indicators are age-varying, and because of the interactions between $t$ and $z(\tau)$.

The estimation results allowing for unobserved heterogeneity show that the variance of the unobserved heterogeneity term is significantly positive. The estimates of the other parameters, however, are similar to those without. Sign, order of magnitude, and significance of the main coefficients are unaffected.

\section{Sensitivity Analyses}

Rather than giving full sets of parameter estimates, we discuss the distinguishing features of each analysis, focusing on the parameters of interest. First, we reestimate the models with samples in which the first 10 -year or 20 -year birth cohorts are fully omitted (recall that these have higher rates of unobserved death dates). The results are very similar to those above. We also estimate model specifications with alternative early-childhood age sets. For example, we consider cyclical indicators for the age sets

\footnotetext{
${ }^{14}$ Using U.S. data from the mid-nineteenth century, Richard H. Steckel (1988) finds that individual wealth as measured by the value of real estate owned by the household head does not have a significant effect on the mortality of infants, children, or adult women. As Steckel (1988) notes, however, this wealth variable is imperfect and, like our social class variable, it may be confounded. The household head's occupation level has a somewhat stronger effect on infant mortality.
} 
$\{1, \ldots, \min \{h, t-1\}\}$, with $h=1, \ldots, 5$ as a determinant of the mortality rate at $t$. The estimates of the effects are similar to the reported estimate with $h=6$, suggesting that even the actual state of the cycle between age one and two does not have important long-run effects on mortality. We also estimate specifications where the dummy cyclical indicators are replaced by the actual (average) values. This does not affect the conclusions either. Cyclical indicators for the age set $\{7, \ldots, \min \{14, t-1\}\}$ and the cyclical indicator for the year prior to birth turn out to be insignificant. The estimation results are insensitive to changes in the age intervals in the age dependence function (for example, if one divides the age interval 35-59 into two intervals 35-49 and 50-59) except, not surprisingly, if one aggregates age intervals at low ages. If we include $z_{t r}(\tau-t)$ in the model, the corresponding coefficient as well as the coefficient on log GNP are nonsensical, confirming that there is insufficient independent variation of these two variables in the data.

Next, we estimate a model in which the effect of the cyclical indicator at birth is allowed to vary with the age of the individual. Specifically, we interact it with an indicator of whether age exceeds 50 . The interaction coefficient is insignificantly different from zero. This suggests that bad economic conditions during childhood do not have a weaker effect on the mortality rate at prime ages, although this should be taken with some caution, first of all because of the small number of observed deaths between ages 5 and 50 , and second because the model specification at high ages is not very elaborate. Note that the absolute effect on mortality at high ages is larger simply because mortality itself is larger at high ages. The interaction of the effect of the cyclical indicator at ages one to six with high age is not significant either. These results do not depend on whether we use the actual (averages of the) cyclical indicators or their rounded-off dummy variables.

Next, we consider other indicators of macroeconomic conditions at birth, notably the inflation rate. Its coefficient is insignificant and close to zero. In fact, inflation seems to be unrelated to movements in real annual per capita GNP. The share of agricultural production in the annual GNP at birth has a positive coefficient, but this variable contains cyclical as well as trend components, so its effect is hard to interpret.
We estimate separate models for men and women. Most parameter estimates are similar to each other and to those reported in Table 3. The cyclical indicator at birth, however, is now insignificant for women, while it is still significant for men. ${ }^{15}$ This suggests that men suffer relatively more heavily from adverse economic conditions at birth. ${ }^{16}$ Conversely, female mortality is significantly more dependent on parents' social class.

We also estimate models with an additional dummy variable for 1866 in $z(\tau)$, because of the nationwide cholera epidemic in that year. The corresponding coefficient is insignificantly positive and very small, so that it can be concluded that the epidemic did not have a sizeable effect on mortality.

Finally, we estimate models that include dummy variables for the season of birth. These turn out to have insignificant effects. At spring, summer, and fall, the estimated effects on the $\log$ mortality rate equal $0.07,0.01$, and -0.03 .

Dehejia and Lleras-Muney (2004) show that in the late-twentieth century the composition of newborns varies with the stage of the cycle at birth. For example, in a recession in that era, among whites, more children are born with loweducated parents, i.e., with lower individual expected lifetimes. We check on this hypothesis in two ways. First, we examine how the number of newborns varies over the cycle, the argument being that a relation between these makes it more likely that the composition changes as well. Second, we examine whether the composition in terms of social class varies over the cycle. It turns out that in both cases we find no relation at all in our data. The slope coefficient of the regression of the log number of births in a birth year on the cyclical component of that year equals 0.13 (with the cyclical component

\footnotetext{
${ }^{15}$ This result is confirmed by nonparametric analyses by gender.

${ }^{16}$ This is in agreement to some other recent evidence. The landmark medical study by D. A. Leon et al. (1998) on the relation between birth weight and mortality from heart disease finds stronger effects for men. Case and Christina Paxson (2005) provide some evidence that men with certain health problems that might originate earlier in life are more likely to die than women with the same conditions. Also, in most countries examined, the long-run mortality effects of the season of birth are smaller for women than for men (Doblhammer, 2004), although these differences are sometimes rather small.
} 
and the log number of births being dispersed in $(-0.1,0.1)$ and $(3.9,5.1)$, respectively). The slope coefficient of the regression of average social class in a birth year on the cyclical component of that year equals 0.00 . There is also no relation with the proportion of newborns from higher social classes.

To conclude this subsection, the main estimation results are qualitatively and quantitatively robust with respect to a wide range of assumptions.

\section{Implications and Policy}

From the second set of results in Table 3, being born in a recession is associated with an 8 -percent increase in the mortality rate after the first year of life. On average, around 25 percent of individuals die in their first year of life, and the total mean lifetime decreases by about 5 percent. This is in line with the nonparametric results. Using the results from Table 3 again, a 5 -percent increase in the mean lifetime can be associated with a 12-percent increase in current GNP, including the effects of all past secular developments. From Figure 1, it follows that this corresponds to being born on average 12 years later in time, that is, to benefiting from 12 years of additional secular developments.

It is possible that the state of the business cycle at birth has a smaller or different long-run effect in the twentieth century. Dehejia and Lleras-Muney (2004) show that being born in a recession in the late twentieth century improves the health of small children because parents' health-related behavior improves (for example, because their opportunity cost of time reduces). ${ }^{17}$ This is an instantaneous effect, but it could suggest that long-run effects are different as well. Recall, however, that our primary interest is in the effect of individual economic conditions at birth on mortality later in life. In the nineteenth century, job loss or income loss could lead to starvation. There were no unemployment benefits and welfare programs to safeguard household income sufficiently. Childbearing was difficult to plan. In this context, cyclical variation can be used to address our issue of primary interest. At the individual level, the presence of an

\footnotetext{
${ }^{17}$ This is in line with Ruhm's (2000) finding that mortality among adults in the late twentieth century is procyclical.
}

effect of economic conditions at birth on mortality later in life does not depend on the effect of the cycle on these conditions.

It could also be argued that long-run effects of early-childhood conditions in Western societies were more important in the nineteenth century than they are now because of the shift in the mortality spectrum from infectious diseases to chronic diseases. Our present data do not enable us to address this. The recent epidemiological literature using natural experiments demonstrates, however, that cohort effects on health and mortality later in life are also significant in the twentieth century (see, e.g., Almond, 2002, and the survey in Doblhammer, 2004). Moreover, our results are confirmed by recent studies of the effects of observed individual socioeconomic conditions on such health outcomes as illness indicators later in life. These studies point toward childhood conditions as crucial determinants of health later in life (see, e.g., Case et al., 2005).

The results indicate that, from a policy standpoint, it is particularly useful to focus on children aged zero in bad economic conditions. The contemporaneous mortality of these children, as well as mortality later in their life, may be significantly reduced if their conditions are improved, for example by way of food, housing, and health care provision.

Recessions in the nineteenth century may also have induced increased insecurity and stress (Brenner, 1979, shows that this effect is also present in the mid-twentieth century). This may also lead to higher long-run mortality rates for newborns. This is a long-run effect from business cycles, by way of turbulence of the parents' economic conditions, to stress, to mortality. This effect may be relative in the sense that its magnitude depends less on the baseline income level than on the turbulence. The presence of such an effect provides a novel reason for the government to stabilize the macroeconomy.

\section{Conclusions}

Using data covering the period 1812-2000, our empirical analysis demonstrates a significant effect of the state of the business cycle at birth on the individual mortality rate later in life. On average, and keeping everything else constant, an individual born in a recession lives 
a few years less than an individual born in a boom. We take the significant effect of cyclical conditions at birth as evidence of a causal negative effect of individual economic conditions early in life on the mortality rate later in life. Note that the former is used to investigate the presence of the latter, but the former effect is not necessary for the latter to be present. In this sense, the relevance stretches beyond the birth cohorts in the data. Indeed, the results are in accordance with other studies on the significance of early life conditions. The results imply that, from a policy point of view, it is particularly useful to focus on children aged zero in bad economic conditions. The contemporaneous mortality of these children, as well as mortality later in their life, may be reduced if their conditions are improved, for example, by way of food, housing, and health care provision. To the extent that the cyclical turbulence creates stress among parents, which in turn creates high mortality later in life among their infants, the results in this paper can be viewed as a justification for macroeconomic stabilization policies.

\section{REFERENCES}

Almond, Douglas V. "Cohort Differences in Health: A Duration Analysis Using the National Longitudinal Mortality Study." University of Chicago, Population Research Center Discussion Paper Series: No. 200213, 2002.

van den Berg, Gerard J. "Duration Models: Specification, Identification and Multiple Durations," in James J. Heckman and Edward Leamer, eds., Handbook of econometrics. Vol. 5. Amsterdam: Elsevier Science, NorthHolland, 2001, pp. 3381-3460.

Brenner, M. Harvey. "Mortality and the National Economy: A Review and the Experience of England and Wales, 1936-1976." The Lancet, 1979, 314(8142), pp. 568-73.

Case, Anne; Fertig, Angela and Paxson, Christina. "The Lasting Impact of Childhood Health and Circumstance." Journal of Health Economics, 2005, 24(2), pp. 365-89.

Case, Anne and Paxson, Christina. "Sex Differences in Morbidity and Mortality." Demography, 2005, 42(2), pp. 189-214.

Cutler, David M. and Meara, Ellen. "Changes in the Age Distribution of Mortality over the
Twentieth Century," in David A. Wise, ed., Perspectives on the economics of aging. Chicago: University of Chicago Press, 2004, pp. 333-65.

Dehejia, Rajeev and Lleras-Muney, Adriana. "Booms, Busts and Babies' Health." Quarterly Journal of Economics, 2004, 119(3), pp. 1091-1130.

Doblhammer, Gabriele. The late life legacy of very early life. Demographic Research Monographs, Max Planck Institute for Demographic Research. Rostock: Max Planck Institute, 2004, ISSN: 1613-5220.

Jacobs, Jan and Smits, Jan-Pieter. "Business Cycles in the Netherlands, 1815-1913." University of Groningen, Research Institute SOM (Systems, Organizations and Management) Research Report Series: No. 01C52, 2001.

Koupilová, Ilona. "Fetal Growth, Social Factors and Circulatory Diseases." Acta Universitatis Upsaliensis. Comprehensive Summaries of Uppsala Dissertations from the Faculty of Medicine, No. 698. Uppsala University, 1997, pp. 7-60.

Leon, David A.; Lithell, Hans O.; Vågerö, Denny; Koupliová, Ilona; Mohsen, Rawya; Berglund, Lars; Lithell, Ulla-Brit and McKeigue, Paul M. "Reduced Fetal Growth Rate and Increased Risk of Death from Ischaemic Heart Disease: Cohort Study of 1,500 Swedish Men and Women Born 1919-29." British Medical Journal, 1998, 317(7153), pp. 241-45.

Mandemakers, Kees. "Historical Sample of the Netherlands," in Patricia K. Hall, Robert McCaa, and Gunnar Thorvaldsen, eds., Handbook of international historical microdata for population research. Minneapolis: Minnesota Population Center, 2000, pp. $149-78$.

Mokyr, Joel. "The Industrial Revolution in the Low Countries in the First Half of the Nineteenth Century: A Comparative Case Study." Journal of Economic History, 1974, 34(2), pp. 365-91.

Murphy, Kevin M. and Topel, Robert H. "The Value of Health and Longevity." National Bureau of Economic Research, Inc., NBER Working Papers: No. 11405, 2005.

van Poppel, Frans and Mandemakers, Kees. "Differential Infant and Child Mortality in Three Dutch Regions, 1812-1912." Economic History Review, 2005, 58(2), pp. 272-309.

Pritchett, Lant and Summers, Lawrence $H$. 
"Wealthier Is Healthier." Journal of Human Resources, 1996, 31(4), pp. 841-68.

Ruhm, Christopher J. "Are Recessions Good for Your Health?" Quarterly Journal of Economics, 2000, 115(2), pp. 617-50.

Smits, Jan-Pieter; Horlings, Edwin and van Zanden, Jan L. "Dutch GNP and Its Components, 1800-1913." University of Groningen, Growth and Development Centre Monograph Series: No. 5, 2000.

Steckel, Richard H. "The Health and Mortality of Women and Children, 1850-1860." Journal of Economic History, 1988, 48(2), pp. 333-45.

De Swaan, Abram. In care of the state: State formation and collectivization of health care, education and welfare in Europe and America in the modern era. Oxford: Oxford University Press, 1988.

Vaupel, James W. and Yashin, Anatoli I. "The Deviant Dynamics of Death in Heterogeneous Populations," in Nancy Tuma, ed., So- ciological methodology 1985. San Francisco: Jossey-Bass Inc., 1985, pp. 179-211.

de Vries, Jan. "Dutch Economic Growth in Comparative-Historical Perspective, 1500-2000." De Economist, 2000, 148(4), pp. 443-67.

Wolleswinkel-van den Bosch, Judith; van Poppel, Frans; Tabeau, Ewa and Mackenbach, Johan P. "Mortality Decline in the Netherlands during the Period 1850-1992: A Turning Point Analysis." Social Science and Medicine, 1998, 47(4), pp. 429-43.

Woods, Robert I.; Watterson, Patricia A. and Woodward, John H. "The Causes of Rapid Infant Mortality Decline in England and Wales, 1861-1921: Part I." Population Studies, 1988, 42(3), pp. 343-66.

van Zanden, Jan Luiten. "Post-War European Economic Development as an Out-ofEquilibrium Growth Path: The Case of the Netherlands." De Economist, 2000, 148(4), pp. 539-55. 